\title{
Towards the STEM DBER Alliance: why we need a discipline-based STEM education research community
}

\author{
Charles Henderson ${ }^{1 *}$, Mark Connolly ${ }^{2}$, Erin L. Dolan ${ }^{3}$, Noah Finkelstein $^{4}$, Scott Franklin ${ }^{5}$, Shirley Malcom ${ }^{6}$, \\ Chris Rasmussen ${ }^{7}$, Kacy Redd ${ }^{8}$ and Kristen St. John ${ }^{9}$
}

\section{(1)What is DBER?}

Discipline-based education research (DBER) is a term that has emerged in the last few decades to describe research that "investigates learning and teaching in a discipline using a range of methods with deep grounding in the discipline's priorities, worldview, knowledge, and practices. It is informed by and complementary to more general research on human learning and cognition" (National Research Council [NRC], 2012, p. 9). DBER seeks to develop evidence-based knowledge and practices that improve teaching and learning in the science, technology, engineering, and mathematics (STEM) disciplines. While new knowledge developed within DBER has led to meaningful improvements in student learning and participation in STEM disciplines (NRC, 2012; Singer \& Smith, 2013), there remain significant opportunities for additional advances (Snow \& Dibner, 2016).

DBER represents a collection of fields that sit at the intersection of a STEM discipline and education research. Although one could imagine DBER occurring within any discipline, the term has so far been used only to describe this type of work within STEM disciplines. An important feature of DBER is the strong role that the discipline plays in setting the priorities for the research and in making sure it is relevant and focused on improving what is most important in moving undergraduates towards expertise in the discipline. Each discipline has bodies of disciplinary content, a culture that shapes how members of the discipline think about and approach their work, and established research methods and tools that practitioners use. Each DBER field combines these discipline-based perspectives with theoretical frameworks and research methodologies from education

\footnotetext{
* Correspondence: charles.henderson@wmich.edu

1Department of Physics and the Mallinson Institute for Science Education, Western Michigan University, 1903 W. Michigan Avenue, Kalamazoo, Ml 49008-5252, USA

Full list of author information is available at the end of the article
}

research (Lohmann \& Froyd, 2011). Figure 1 shows that the field of engineering education research exists at the intersection of the disciplines of engineering and education research. One result of this intersection, for example, is that engineering education researchers frequently make use of qualitative and mixed methods research methodologies that are more common in education research than in traditional engineering fields.

The National Academies' DBER report (NRC, 2012) helped legitimize DBER work within individual STEM disciplines and bring the term DBER into common usage (Rasmussen \& Wawro, in press). Within individual STEM disciplines, "recognition of DBER can be seen in statements by professional societies, the establishment of journals, and the emergence of graduate and postdoctoral opportunities" (National Research Council, 2012, p. 20). There are also a growing number of DBER faculty positions each year at all types of higher education institutions (Bush, Rudd, Stevens, Tanner, \& Williams, 2016).

While significant growth in DBER has occurred within individual STEM disciplines, there has been minimal cross-discipline work. Individual STEM DBER fields, such as physics education research or biology education research, developed independently and have largely remained separate, with separate conferences, journals, and research interests. Opportunities for cross-discipline work also exist between STEM DBER fields and nonSTEM disciplines, such as cognitive science, higher education, and economics.

Building on prior discussions across DBER communities, at the Transforming Research in Undergraduate STEM Education (TRUSE) conference, held on November 18-19, 2016, the American Association for the Advancement of Science and the Association of Public and Land-grant Universities brought together a group of 26 thought leaders from the DBER communities to begin articulating the affordances of developing an intersectional DBER community, 


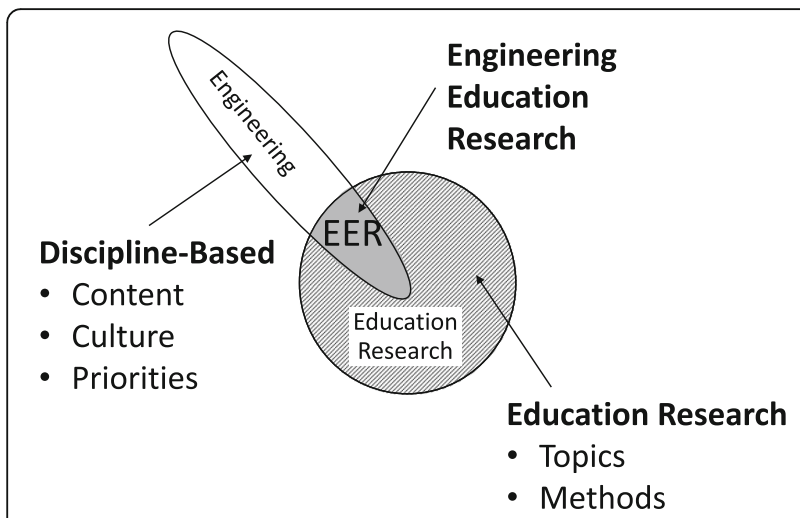

Fig. 1 Each DBER field exists at the intersection of a STEM discipline and the discipline of education research (image based on initial conceptualization by Mark Connolly)

envisioning what structures might best support such a community, and developing plans for advancing this agenda (O’Neil, 2017). It quickly became clear that tremendous advantage and synergy could be gained through the formation of an overarching DBER community that spans disparate disciplines (Talanquer, 2014). We have begun to refer to such a community as the STEM DBER Alliance (DBER-A). As shown in Fig. 2, DBER-A exists at the intersection of multiple DBER fields.

This editorial begins to articulate the rationale for such a community by exploring two important questions. First, what could an allied STEM DBER community accomplish that cannot be accomplished now by individual STEM DBER fields? Second, how could different stakeholders-individual faculty, the DBER community, and broader society-each benefit from such a STEM DBER alliance? Developing and maintaining such a community

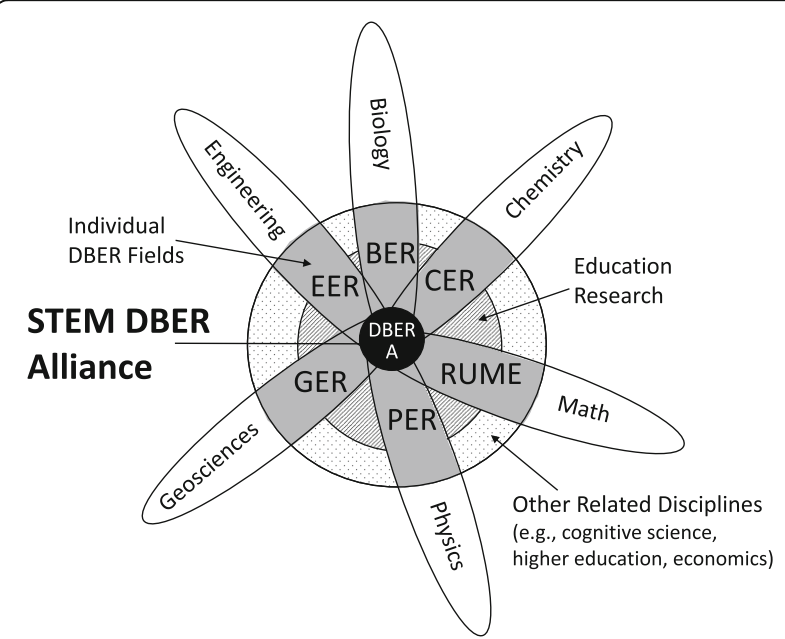

Fig. 2 The STEM DBER Alliance exists at the intersection of multiple DBER fields (image based on initial conceptualization by Mark Connolly) is not without costs, both real costs and opportunity costs. So, it is important to have compelling reasons to move forward.

\section{What can a cross-discipline STEM DBER Alliance do?}

We envision a cross-discipline STEM DBER community engaging in five basic activities. These occur on a spectrum from activities that can be done within an individual DBER field, but might be facilitated by DBER-A, to activities that require committed collaboration of multiple DBER fields. Figure 3 summarizes each type of activity and provides a brief example. The existence of the STEM DBER Alliance is increasingly important as the integration of ideas and development of shared frameworks increases from left to right in the figure.

\section{What is the value of establishing a cross-discipline STEM DBER alliance?}

The value of DBER-A exists at multiple levels. In this section, we identify three basic levels where value could be realized. The first is the value to individual DBER researchers. These researchers will be those who will need to work to create and maintain such a community; the community will not exist if researchers do not find value in it. The second level is the DBER-A community itself as well as each individual DBER field. Communities, including research communities, form and are maintained because groups and individuals working together are, under the right conditions, capable of accomplishing more than these groups or individuals could accomplish working alone (National Research Council, 2005; Nersessian \& Newstetter, 2014; Uzzi, Mukherjee, Stringer, \& Jones, 2013). Therefore, the community we envision will behave in many ways as a community of practice (Kastens, 2017; Wenger-Trayner \& Wenger-Trayner, 2015) that supports individual researchers while simultaneously accumulating and creating community-wide capacity to improve DBER practice.

Finally, the third level is the value to the larger society. One of the core values of DBER is to advance STEM education, which has strong value to society by improving science literacy (Snow \& Dibner, 2016), increasing workforce development (Malcom, Comedy, \& Grant, 2015), broadening participation in STEM (National Science Foundation, 2013, National Science Foundation and National Center for Science and Engineering Statistics, 2017), and addressing complex societal challenges of health, the environment, climate, energy, and national security (Levy \& Plucker, 2015). By integrating STEM education, DBER-A can support increased work towards tackling these important problems that are most effectively addressed across DBER.

Of course, these levels of value for a cross-disciplinary STEM DBER Alliance do not exist independently, and 


\begin{tabular}{|c|c|c|c|c|}
\hline $\begin{array}{l}\text { Facilitated by } \\
\text { DBER Alliance }\end{array}$ & & & & $\begin{array}{l}\text { Situated in } \\
\text { DBER Alliance }\end{array}$ \\
\hline $\begin{array}{l}\text { Develop understanding } \\
\text { of other context }\end{array}$ & $\begin{array}{l}\text { Transfer of research } \\
\text { ideas/methods }\end{array}$ & Collaborative research & Cross-cutting research & $\begin{array}{c}\text { Research community } \\
\text { development }\end{array}$ \\
\hline $\begin{array}{l}\text { Physics requires under- } \\
\text { standing of biology to } \\
\text { develop a physics } \\
\text { course for biology } \\
\text { majors. }\end{array}$ & $\begin{array}{l}\text { Math education re- } \\
\text { search learns ideas and } \\
\text { approaches from engi- } \\
\text { neering education re- } \\
\text { search to study problem } \\
\text { solving. }\end{array}$ & $\begin{array}{l}\text { Chemistry and geosci- } \\
\text { ences education re- } \\
\text { searchers engage in } \\
\text { cross-disciplinary re- } \\
\text { search to improve how } \\
\text { the teaching of "energy" } \\
\text { can be coordinated } \\
\text { across multiple } \\
\text { disciplines. }\end{array}$ & $\begin{array}{l}\text { Engineering, math, and } \\
\text { physics collaborate on } \\
\text { research that spans all } \\
\text { DBER disciplines toward } \\
\text { improving inclusion and } \\
\text { diversity. All DBER disci- } \\
\text { plines benefit from this } \\
\text { process. }\end{array}$ & $\begin{array}{l}\text { Multiple disciplines in- } \\
\text { teract to set norms (im- } \\
\text { plicit or explicit) for dis- } \\
\text { cipline-based education } \\
\text { research on how stu- } \\
\text { dent learning gets re- } \\
\text { ported. DBER-A (and all } \\
\text { DBER disciplines) } \\
\text { benefit. }\end{array}$ \\
\hline
\end{tabular}

Fig. 3 Five basic types of interaction between the individual DBER fields that are expected to take place within the STEM DBER Alliance

there is significant overlap. Yet, it is useful to think about the levels separately because each level has a different target audience and a different value proposition for that target audience.

First, the value of DBER-A to individual researchers consists of connecting researchers and legitimizing the work of individuals. A range of efforts can advance individual researchers:

Organizing conferences and workshops where researchers across DBER fields can interact and new collaborations can be developed.

Developing mechanisms, such as conferences, journals, and webinars, for researchers to share strategies, methodologies, and results.

Establishing new recognitions (awards, invited talks, etc.) that enhance the status of individual researchers and the DBER community.

Establishing a recognized organization that can sanction DBER activities, to add legitimacy to DBER work and organizational functionality for meeting cross-DBER goals.

Establishing mechanisms for researchers to develop and identify allies in other DBER disciplines on their campuses.

Opening doors to new funding directions for individuals to draw upon.

Second, the value of DBER-A to the DBER community itself and to individual DBER fields consists of creating a common voice to effectively advocate for DBER and provide a forum for community reflection and development. A range of efforts can advance the DBER community:

Presenting a common message to individual disciplinary societies to enhance the status of individual DBER fields and researchers.

Presenting individual DBER fields within the landscape of an interdisciplinary endeavor solidifies the position of each.

Presenting a common message to funding agencies and policy makers that will avoid pitting one DBER field against another for funding and will promote collaborations across DBER fields.

Presenting a unified message to political agencies, such as the national academies, federal and state departments, and legislators, to provide critical support to STEM areas, such as climate science, that may be subject to heightened political scrutiny.

Casting a wider net to diversify and enlarge the DBER community and provide professional development to potential DBER researchers.

Expanding and diversifying the publication venues and reviewer pool for DBER work.

Increasing the potential for meta-analyses and systematic reviews of published studies that span multiple disciplines; in turn, increasing the strength of evidence for making community claims and recommendations for improving STEM teaching practice and student learning.

Finally, the value of DBER-A to the broader society is improvement in STEM education for all students at all levels.

Improving student learning and participation in STEM disciplines by accelerating the rate of knowledge development and dissemination within DBER. Increasing the effectiveness of development and implementation of high-impact educational practices by enhancing collaboration within DBER and between DBER and other related communities, such as the faculty professional development community and the scholarship of teaching and learning community. Improving the scientific, technical, and quantitative literacy of the general population by promoting coordination and alignment across the STEM disciplines. This is necessary for the public to make good decisions about the significant science- and technologyrelated challenges facing our country and planet. Improving the ability of the STEM education community to develop more equitable educational environments that lead to a more diverse and productive STEM workforce. 
Fostering interactions between K-12 and college STEM education researchers, policy makers, and other stakeholders to strengthen system-wide educational practices and alignment.

\section{(2)Next Steps}

We have argued for the formation of a STEM DBER Alliance. Exploratory discussions have found sufficient agreement about its potential value for us to begin work to develop such a community (O'Neil, 2017). How this community should be structured will need to be considered carefully to account for the perspectives and needs of the wide variety of potential stakeholders. Success will depend on building a community structure that incorporates reinforcing mechanisms so that the benefits are realized across the individual-community-society spectrum.

We invite you to join us in this work. We have formed a DBER-A group in the AAAS collaboration web hub, Trellis, and encourage you to join (http://www.trelliscience.com/DBER-A/). In the coming months we will be initiating face-to-face discussions at workshops and national conferences, such as those sponsored by the American Educational Research Association or National Association for Research in Science Teaching. We also request contributions of strong examples of DBER-A work that can be used to demonstrate productive outcomes and approaches from work across individual DBER fields.

\footnotetext{
Author details

${ }^{1}$ Department of Physics and the Mallinson Institute for Science Education Western Michigan University, 1903 W. Michigan Avenue, Kalamazoo, MI 49008-5252, USA. ${ }^{2}$ Wisconsin Center for Education, University of Wisconsin, Research, 1025 W. Johnson St., 570A Educational Sciences Bldg., Madison, WI 53706, USA. Innovative Science Education, University of Georgia, B210B, Davison Life Sciences, Athens, GA 30602, USA. ${ }^{4}$ University of Colorado Boulder, UCB 390, Boulder, CO 80309-0930, USA. ${ }^{5}$ Rochester Institute of Technology, Center for Advancing STEM Teaching, Learning \& Evaluation, 1 Lomb Memorial Drive, Rochester, NY 14623-5603, USA. ${ }^{6}$ Education and Human Resources Programs at the American, Association for the Advancement of Science, 1200 New York Avenue, N.W., Washington, D.C. 20005, USA. ${ }^{7}$ Department of Mathematics and Statistics, San Diego State University, 5500 Campanile Drive, San Diego, CA 92182-7720, USA.

${ }^{8}$ Association of Public and Land-grant Universities, 1307 New York Ave N.W. Washington, DC 20005, USA. ${ }^{9}$ James Madison University, 395 S. High Street, Harrisonburg, VA 22807, USA.
}

Received: 3 July 2017 Accepted: 27 July 2017

Published online: 21 August 2017

\section{References}

Bush, S. D., Rudd II, J. A., Stevens, M. T., Tanner, K. D., \& Williams, K. S. (2016). Fostering change from within: influencing teaching practices of departmental colleagues by science faculty with education specialties. PloS One, 11(3), e0150914 https://doi.org/10.1371/journal.pone.0150914.

Kastens, K. (2017). A community of practice for GER. https://nagt.org/nagt/ geoedresearch/toolbox/basics/CoP.html. Accessed 7 Aug 2017.

Levy, H. O., \& Plucker, J. A. (2015). Brains, not brawn: America's lack of STEM students is bad news for national security. U.S. News \& World Report. http://www.usnews.com/news/the-report/articles/2015/06/05/lack-of-stemstudents-is-bad-for-national-security. Accessed 7 Aug 2017.

Lohmann, J., \& Froyd, J. (2011). Chronological and ontological development of engineering education as a field of scientific inquiry. Paper presented at the Second Committee Meeting on the Status, Contributions, and Future Directions of
Discipline-Based Education Research. (http:/sites.nationalacademies.org/cs/groups/ dbassesite/documents/webpage/dbasse_072587.pdf. Accessed 7 Aug 2017.

Malcom, S., Comedy, Y. L., \& Grant, C. (2015). Education and workforce development in the budget. In The President's FY 2016 Budget (Chapter 4). Washington, DC: American Association for the Advancement of Science. https:/www.aaas.org/ fy16budget/education-and-workforce-development-budget. Accessed 7 Aug 2017.

National Research Council. (2005). Facilitating interdisciplinany research. Washington, DC: The National Academies Press. https:/doi.org/10.17226/11153. Accessed 7 Aug 2017.

National Research Council. (2012). Discipline-based education research: understanding and improving learning in undergraduate science and engineering, S. R. Singer, N. R. Nielsen, \& H. A. Schweingruber (Eds.), Washington, DC: The National Academies Press. http://www.nap.edu/catalog. php?record_id=13362. Accessed 7 Aug 2017.

National Science Foundation. (2013). Inspiring STEM learning (NSF report 13-800). https:/www.nsf.gov/about/congress/reports/ehr_research.pdf. Accessed 7 Aug 2017.

National Science Foundation, National Center for Science and Engineering Statistics. (2017). Women, minorities, and persons with disabilities in science and engineering (NSF report 17-310). Arlington, VA: National Science Foundation. www.nsf.gov/statistics/wmpd/. Accessed 7 Aug 2017.

Nersessian, N. J., \& Newstetter, W. C. (2014). Interdisciplinarity in engineering research and education. In A. Johri \& B. M. Olds (Eds.), Cambridge handbook of engineering education research (pp. 713-730). New York, NY: Cambridge University Press.

O'Neil, K. (2017). Experts seek to boost knowledge and allies for teaching STEM. Washington, DC: American Association for the Advancement of Science. http://www.aaas.org/news/experts-seek-boost-knowledge-and-allies-teachingstem. Accessed 7 Aug 2017.

Rasmussen, C., \& Wawro, M. (in press). Post-calculus research in undergraduate mathematics education. In J. Cai (Ed.), The compendium for research in mathematics education. National Council of Teachers of Mathematics: Reston VA.

Singer, S., \& Smith, K. A. (2013). Discipline-based education research: understanding and improving learning in undergraduate science and engineering. Journal of Engineering Education, 102(4), 468-471 http://doi.org/ 10.1002/jee.20030.

Snow, C. E., \& Dibner, K. A., (2016). Science literacy: concepts, contexts, and consequences. Washington, DC: National Academies Press. http://sites. nationalacademies.org/DBASSE/BOSE/Science_Literacy/index.htm. Accessed 7 Aug 2017.

Talanquer, V. (2014). DBER and STEM education reform: are we up to the challenge? Journal of Research in Science Teaching, 51(6), 809-819 http://doi.org/10.1002/tea.21162.

Uzzi, B., Mukherjee, S., Stringer, M., \& Jones, B. (2013). Atypical combinations and scientific impact. Science, 342(6157), 468-472.

Wenger-Trayner, E., \& Wenger-Trayner, B. (2015). Introduction to communities of practice: a brief overview of the concept and its uses [Webpage]. http://wenger-trayner.com/introduction-to-communities-of-practice/. Accessed 7 Aug 2017.

\section{Submit your manuscript to a SpringerOpen ${ }^{\mathcal{O}}$ journal and benefit from:}

- Convenient online submission

- Rigorous peer review

- Open access: articles freely available online

- High visibility within the field

- Retaining the copyright to your article

Submit your next manuscript at $>$ springeropen.com 